\title{
Medição de desempenho na construção civil: um estudo exploratório com construtoras cearenses
}

\author{
Performance measurement systems in the construction \\ industry: an exploratory study in construction companies \\ from Ceará, Brazil
}

\section{Domingos Sávio Viana de Sousa Luis Felipe Cândido J osé de Paula Barros Neto}

\section{Resumo}

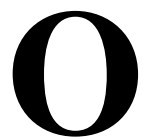

presente trabalho tem por objetivo identificar as oportunidades de melhoria para a medição de desempenho a partir de um estudo de caso múltiplo com quatro construtoras de Fortaleza, CE. Para tal, foram realizadas dez entrevistas semiestruturadas com intervenientes de diferentes níveis hierárquicos das empresas, além de terem sido analisados documentos comprobatórios. Foram identificadas lacunas de desempenho, a partir das quais se realizou a proposição de onze melhorias para os processos das empresas estudadas e para a melhoria do campo do conhecimento em medição de desempenho. Conclui-se que, devido às deficiências observadas, os sistemas de medição não contribuem para a gestão das empresas efetivamente, uma vez que as informações geradas não conseguem enfatizar as verdadeiras lacunas de desempenho da empresa, bem como proporcionar um estilo de gestão proativo para as mudanças do mercado, o que diminui sua capacidade competitiva.

Palavras-chave: Medição de desempenho. Indicadores de desempenho. Gestão. Estratégia. Estudo de caso.

Domingos Sávio Viana de Sousa Universidade Federal do Ceará Fortaleza - CE - Brasil

Luis Felipe Cândido Centro Universitário Christus Fortaleza - CE - Brasil

J osé de Paula Barros Neto Universidade Federal do Ceará Fortaleza - CE - Brasil

Recebido em 25/02/17 Aceito em 14/07/17

\section{Abstract}

The aim of this paper is to identify opportunities to improve performance measurement systems in the construction industry by using a multiple case study conducted in four construction companies in the city of Fortaleza, Brazil. With that purpose, ten semi-structured interviews were carried out with managers at different hierarchical levels. In addition to the interviews, documents were collected to support the interview claims. Performance gaps were identified and, based on them, eleven measures were proposed to improve the companies' processes and to enhance the knowledge in performance measurement. The study concluded that PMS do not effectively contribute to the management of the companies because the information generated does not emphasize the actual performance gaps; neither do they offer a proactive management style that is capable of dealing with the demands of the market, which decreases the companies' competitiveness.

Keywords: Performance measurement. Performance indicators. Strategic management. Case study. 


\section{Introdução}

A gestão das empresas está cada vez mais complexa na economia de competição em escala global. As empresas vêm se transformando para atender às novas condições no cenário produtivo, em que a busca e a importância da inovação, a redução do ciclo de vida dos produtos (CHIESA; FRATTINI, 2007), a internacionalização dos processos produtivos, a aceleração das relações comerciais, facilitada por avanços da tecnologia da informação (KUHL; KUHL; GUSMÃO, 2014), são características marcantes e tornam o ambiente de negócio desafiador e imprevisível.

Tal cenário vem se consolidando desde a década de 1980 e provocou a mudança das estratégias baseadas em liderança de custo para diferenciação/customização, as quais passaram a demandar a evolução da medição de desempenho das empresas (TONI; TONCHIA, 2001). Porém, avaliar o desempenho organizacional é um dos requisitos mais desafiadores para as organizações (EVANS, 2004).

Entre os vários setores que mudaram suas estratégias competitivas e que também demandam melhorias para os processos de medição, pode-se destacar a indústria da construção. Diversos esforços têm sido empreendidos por acadêmicos e profissionais para entender como as empresas poderiam informar a seus stakeholders (CÂNDIDO; LIMA; BARROS NETO, 2016), tanto no âmbito da indústria (HORTA; CAMANHO; COSTA, 2010; HU; LIU, 2016) como no da organização (JIN et al., 2013; MAYA, 2016), projetos (ASMAR; HANNA; LOH, 2016) e processos específicos (GEORGY; CHANG; ZHANG, 2005).

O fato é que a medição de desempenho na construção é considerada como um dos principais desafios à gestão do setor, principalmente a medição do progresso do trabalho em nível operacional (SAIDI; LYTLE; STONE, 2003). Nesse sentido, observa-se que as principais iniciativas para a melhoria da medição de desempenho são os clubes de benchmarking (COSTA et al., 2006), os quais oferecem às empresas um conjunto de indicadores de desempenho para se autoavaliarem e compararem seus desempenhos com os de seus concorrentes (COSTA et al., 2006).

Porém, a implantação de um processo de medição é distinta e vai além do uso de indicadores de desempenho, sendo um processo cíclico de gestão mais abrangente (CÂNDIDO; LIMA; BARROS NETO, 2016). Por isso, entre outras razões, apesar de tais iniciativas, a evolução para os sistemas de medição no setor da construção é lenta (DENG; SMYTH; ANVUUR, 2012; KORDE; LI; RUSSELL, 2005; NUDURUPATI; ARSHAD; TURNER, 2007).

No Brasil não é diferente. Apesar de as empresas terem iniciado o uso de indicadores na década de 1980 (BARBOSA, 2010), há um descompasso entre teoria e prática da medição de desempenho (COSTA, 2003). Essa questão continua em aberto e necessita de mais estudos que permitam, entre outros pontos, estabelecer diretrizes operacionais mais contundentes para que os benefícios das sistemáticas de medição das empresas sejam efetivamente alcançados (CÂNDIDO; LIMA; BARROS NETO, 2016).

Isso se torna mais crítico devido à complexidade inerente à indústria da construção civil, caracterizada pela natureza única dos projetos com local e equipe de gestão temporários (KOSKELA, 1992), a existência de diferentes stakeholders, que seguem diferentes processos de negócios e possuem, muitas vezes, interesses conflitantes (WEGELIUS-LEHTONEN, 2001), e a fragmentação dos processos (HORSTMAN; WITTEVEEN, 2013).

Assim, considerando a alta influência que as características organizacionais e ramo de atuação exercem sobre a medição de desempenho (CHIESA; FRATTINI, 2007), este estudo explora a seguinte questão de pesquisa: quais as principais características, papéis e processos dos sistemas de medição de desempenho de empresas construtoras?

Destarte, o presente trabalho tem por objetivo analisar por meio de um estudo de caso múltiplo e exploratório as características, os papéis e os processos dos sistemas de medição de desemoenho (SMD) de quatro empresas de construção civil da cidade de Fortaleza. Busca-se identificar oportunidades de melhoria para o campo do conhecimento e enfatizar aspectos operacionais, de forma a contribuir para as demandas apresentadas por Cândido, Lima e Barros Neto (2016).

Ademais, diferentemente da maioria dos estudos sobre medição no setor da construção, que focam na análise dos indicadores, este estudo está focado nas características para a correta e efetiva utilização dos sistemas de medição de desempenho nas empresas do setor.

\section{Referencial teórico}

A presente seção apresenta o referencial teórico estabelecido para o presente trabalho, o qual aborda inicialmente a medição de desempenho a partir das 
disciplinas de gestão e, em seguida, faz-se um recorte para a literatura específica da construção civil.

\section{Medição de desempenho}

A medição de desempenho pode ser definida como “[...] o processo de quantificar a eficiência e a efetividade de uma ação [...]” (NEELY; GREGORY; PLATTS, 1995, p. 80). Segundo Bititci, Carrie e Mcdevitt (1997), é o centro do processo de gestão de desempenho e funciona como sistema de informação que permite o feedback em ciclo fechado e que integra todas as informações relevantes dos sistemas gerenciais da empresa, corroborando a ideia de gestão de desempenho apresentada por Lebas (1995).

Entende-se que a medição vai além da geração de indicadores de desempenho. Existe, por exemplo, a etapa de gerenciamento do desempenho, quando a avaliação dos resultados e consequentemente as intervenções são praticadas (LEBAS, 1995).

Assim, todo esforço para melhorar as ações e procedimentos de trabalho na busca das metas e objetivos da empresa pode ser encarado como a gestão do desempenho (LEBAS, 1995), enquanto a tarefa de aferir a efetividade desse esforço pode ser encarada como a medição de desempenho (LEBAS, 1995; NEELY; GREGORY; PLATTS, 1995).

Porém, indiferente à definição, o papel da medição de desempenho é indiscutível. É uma das mais poderosas disciplinas de gestão, pois é capaz de transformar em realidade a missão ou a estratégia de uma organização (MAGRETTA; STONE, $2002^{1}$ apud MELNYK; STEWART; SWINK, 2004).

Nesse contexto, existe uma corrente de pesquisadores que tratam a medição de desempenho como um sistema, embora as abordagens para o estudo deles não tenham base na Teoria Sistêmica (CHOONG, 2013a). Essa visão deriva da necessidade de se estabelecer uma congruência entre as partes que compõem a medição de desempenho para que seja possível efetivar os benefícios que ela fornece às empresas, focando-se em uma visão mais pragmática (de um produto) do que uma concepção aberta, intrínseca ou organizacional (KUENG; ANDREAS; WTTSTEIN, 2001).

Assim, Kueng, Andreas e Wttstein (2001) apontam que, se pensada como sistema, a medição de desempenho possui cinco componentes:

(a) pessoas;
(b) processos;
(c) dados;
(d) software; e
(e) hardware.

Já Lohman, Fortuin e Wouters (2004) possuem a visão dos componentes de um SMD mais vinculados a sistemas de informação:
(a) software;
(b) banco de dados; e
(c) processos.

Para Chiesa e Frattini (2007), um sistema de medição é constituído de:
(a) propósito;
(b) dimensões de desempenho;
(c) indicadores;
(d) estrutura; e
(e) processo de medição.

Essas tentativas têm como objetivo final conhecer as características, os usos e os processos que compõem a medição de desempenho (CHOONG, 2013a, 2013b; FRANCO-SANTOS et al., 2007; FRANCO-SANTOS; LUCIANETTI; BOURNE, 2012), o que tem levado à busca por melhorias para a efetivação dos modelos existentes nas empresas (TATICCHI; TONELLI; CAGNAZZO, 2010).

Não obstante, diferentemente de Kueng, Andreas e Wttstein (2001), de Lohman, Fortuin e Wouters (2004) e de Chiesa e Frattini (2007), que investigaram a temática a partir da experiência em empresas, Franco-Santos et al. (2007) analisaram a literatura e propuseram as características, papéis e processos essenciais para a medição de desempenho em qualquer empresa.

Considerando como visão teórica o trabalho de Franco-Santos et al. (2007) e o trabalho de Chiesa e Frattini (2007) como visão empírica (mais completa entre os trabalhos supracitados), observa-se grande correspondência entre as proposições, conforme o Quadro 1.

A definição e a seleção de indicadores de desempenho ainda são um desafio para os gestores (NEELY; BOURNE, 2000), uma vez que a decisão sobre o que medir relaciona-se com a definição de quais informações são necessárias para gerenciar o sistema (NEELY et al., 2000; SINK; TUTTLE, 1993). No entanto, muitas vezes o próprio sistema 
gerencial não está bem delimitado, o que conduz a erros como:

(a) medir coisas erradas; ou

(b) medir tudo o que puder ser medido (NEELY; BOURNE, 2000).

A etapa de coleta e processamento dos dados enfoca a criação dos dados necessários, a forma como estes são transformados em informações e como devem ser apresentados para fornecer apoio à gestão. Consiste em decidir como armazenar e recuperar os dados de forma eficaz e eficiente. Além disso, consiste em escolher a forma de validação das informações (SINK; TUTTLE, 1993).

Parece uma etapa simples, porém se deve considerar o usuário da informação de forma a facilitar "[...] a passagem da fase de representação das informações para a interface de decisão para ação [...]” (SINK; TUTTLE, 1993, p. 259), ou seja, uma vez definida qual a informação necessária, deve-se definir também como essa informação será coletada e processada.

Após a coleta e processamento dos dados, o sistema de medição deve ser capaz de fazer fluir a informação. Essa etapa envolve a manutenção do sistema de feedbacks, o que garante que a informação chegue a seu destinatário e que a interpretação e a tomada de decisão sejam realizadas (FRANCO-SANTOS et al., 2007).

Segundo Scanlin (1998), o processo de comunicação consome de $75 \%$ a $90 \%$ do tempo dos gestores e é citado como uma das principais causas de falhas nos projetos. Por esta razão, entre outras, a gestão da informação deve ser "[...] capaz de desenvolver e capacitar pessoas, no que tange ao uso da informação e à produção de conhecimentos [...]” (BARRETO, 2006, p. 55).

Nesta etapa procura-se vincular as informações geradas pelo SMD às ações e decisões (SINK; TUTTLE, 1993). A informação gerada deve promover o “[...] aprendizado estratégico que consiste do feedback, do teste das hipóteses em cuja estratégia foi baseada e realização dos ajustes necessários [...]” (KAPLAN; NORTON, 1996, p. 12).

Por fim, é consenso na literatura a natureza dinâmica do ambiente competitivo em que as empresas operam, e, como tal, seus processos devem ser evolutivos, tendo em vista a manutenção da competitividade e da própria existência da organização. Sendo um processo organizacional, a medição de desempenho não foge à regra, e sua revisão sistemática é citada como fundamental por muitos autores.

Assim, esclarecidos os processos considerados como essenciais por Franco-Santos et al. (2007), adotou-se o framework proposto pelos autores para analisar as características, papéis e processos das empresas construtoras selecionadas para o presente estudo.

\section{Quadro 1 - Componentes de um SMD: visão teórica versus empírica}

\begin{tabular}{|c|c|}
\hline Visão teórica - Franco-Santos et al. (2007) & Visão empírica - Chiesa e Frattini (2007) \\
\hline \multicolumn{2}{|l|}{ Características } \\
\hline Possui indicadores de desempenho & Possui indicadores de desempenho \\
\hline Tem uma infraestrutura de suporte estabelecida & Possui infraestrutura de suporte \\
\hline \multicolumn{2}{|l|}{ Papéis } \\
\hline Medir o desempenho & Aumentar o desempenho \\
\hline Gerir a estratégia & $\begin{array}{l}\text { Reduzir os riscos } \\
\text { Apoiar a tomada de decisão }\end{array}$ \\
\hline Comunicar & Aumentar a comunicação e a coordenação \\
\hline Influenciar o comportamento & $\begin{array}{l}\text { Motivar o pessoal } \\
\text { Apoiar o esquema de incentivo }\end{array}$ \\
\hline Proporcionar aprendizado e melhoria & Promover o aprendizado organizacional \\
\hline \multicolumn{2}{|l|}{ Processos } \\
\hline Selecionar e definir os indicadores & Definir os indicadores \\
\hline Coletar e processar os dados & Coletar e elaborar os indicadores \\
\hline Gerenciar a informação & \multirow{2}{*}{ Analisar os resultados e identificar ações corretivas } \\
\hline Avaliar e premiar & \\
\hline Revisar o sistema & Medir com frequência \\
\hline
\end{tabular}

Fonte: elaborado a partir de Chiesa e Frattini (2007) e de Franco-Santos et al. (2007). 


\section{Medição de desempenho na construção}

No que se refere aos estudos de medição de desempenho na construção, verifica-se que tradicionalmente os indicadores de desempenho são focados em aspectos financeiros, em especial na lucratividade (HU; LIU, 2016), apesar de, há muito tempo, estudos mostrarem que indicadores financeiros não são suficientes para a gestão das empresas, uma vez que não estimulam a melhoria contínua (GHALAYINI; NOBLE, 1996).

Assim, ainda que de forma lenta (DENG; SMYTH; ANVUUR, 2012; KORDE; LI; RUSSELL, 2005; NUDURUPATI; ARSHAD; TURNER, 2007), os sistemas de medição de desempenho têm evoluído no setor da construção (ROBINSON et al., 2005) e introduziram medidas quantitativas e qualitativas relativas às novas dimensões competitivas, buscando monitorar resultados de longo prazo mais vinculados a suas estratégias (COSTA, 2003).

Isso tem tornado mais complexo o processo de medição de desempenho, requerendo a evolução dos modelos de medição para modelos mais generalizados, os quais têm como principal base conceitual o Balanced Scorecard (KAPLAN; NORTON, 1992) e os modelos de excelência em gestão baseados em princípios da qualidade total (EUROPEAN..., 2017).

Porém, independentemente da base conceitual, em essência as empresas têm buscado:

(a) de forma unânime na literatura pesquisada, avaliar o desempenho organizacional dos negócios no mínimo em termos econômico-financeiros [medir o desempenho];

(b) avaliar sua competitividade e posição ante seus concorrentes (COSTA et al., 2004; ELMASHALEH; MINCHIN JUNIOR; O’BRIEN, 2007; HORTA; CAMANHO; COSTA, 2010) [gerir a estratégia];

(c) medir o sucesso de seus produtos finais, ou seja, o impacto sobre seus clientes (BACCARINI, 1999), e analisar sua participação no mercado (BASSIONI; PRICE; HASSAN, 2005; HORTA; CAMANHO; COSTA, 2010; YU et al., 2007) [comunicar os resultados]; e (d) obter medidas capazes de identificar áreas problemáticas e verificar por que elas estão nessa situação (JIN et al., 2013), ou seja, avaliarem seus processos gerenciais a fim evoluir continuamente [influenciar o comportamento e proporcionar aprendizado e melhoria].

Por fim, observa-se que Cândido, Lima e Barros Neto (2016) sintetizaram grande parte de modelos de medição da literatura específica de construção e possibilitaram o entendimento dos elementos no âmbito da construção, também baseados em Franco-Santos et al. (2007). No entanto, como limitação, os referidos autores apontam o caráter teórico da pesquisa, não tendo sido realizada a análise de seu estudo em empresas construtoras, o que é pretendido pela presente pesquisa, cujo método é apresentado a seguir.

\section{Método}

A presente pesquisa enquadra-se como qualitativa, com objetivos exploratórios e descritivos (COLLIS; HUSSEY, 2005), ou seja, busca entender “[...] como (processo) e por que (significado) as coisas acontecem [...]” (COOPER; SCHINDLER, 2016, p. 145), baseando-se essencialmente em dados não mensuráveis, podendo ser na forma de texto, imagem, som, e buscando extrair os significados múltiplos de um fenômeno (RICHARDSON, 2011).

Como estratégia de pesquisa aplicou-se o estudo de caso múltiplo (YIN, 2010), que investiga um fenômeno contemporâneo dentro de seu contexto real (GIL, 2008; ROESCH, 2006; YIN, 2010) e com entrevistas semiestruturadas (GRAY, 2012; RICHARDSON, 2011), como dados primários, e documentos (BELTRÃO; NOGUEIRA, 2011; CELLARD, 2010), como dados secundários.

Para a consolidação dos resultados aplicou-se a análise de conteúdo (CHIZZOTI, 2011; FOSSÁ, 2003; GIBBS, 2009; KRIPPENDORFF, 2004) e a análise documental (BELTRÃO; NOGUEIRA, 2011; CELLARD, 2010).

A Figura 1 apresenta o delineamento da pesquisa. 
Figura 1 - Delineamento da pesquisa

- Medição de desempenho na indústria

- Medição de desempenho na indústria da construção

- Indicadores de desempenho

na indústria da construção

- Elaboração do roteiro de entrevista

$1^{\text {a }}$ Etapa: Estudo teórico $2^{\mathrm{a}}$ Etapa: estudos de caso

- Adoção do framework proposto por Franco-Santos et al. (2007) para análise do processo das empresas - 10 entrevistas em 4 empresas construtoras
-Significado de medição de desempenho para as empresas

- Indicadores das empresas - Análise dos processos de medição das empresas, conforme etapas de FrancoSantos et al. (2007). - Proposição de melhorias

$3^{\text {a }}$ Etapa: oportunidades de melhorias

\section{1a etapa: estudo teórico}

A partir da revisão da literatura, a entrevista semiestruturada foi elaborada em três partes:

(a) caracterização da empresa - para identificar as características organizacionais que influenciam a estruturação do sistema de medição de desempenho (CHIESA; FRATTINI, 2007);

(b) visão da empresa sobre medição de desempenho - para identificar o significado do processo de medição para os participantes do estudo, uma vez que a literatura aponta que tal significado está limitado a resultados de curto prazo e essencialmente vinculado à visão econômico-financeira (HU; LIU, 2016); e

(c) caracterização do sistema de medição de desempenho da empresa - baseado no framework de Franco-Santos et al. (2007) e subdividido em cinco processos:

- selecionar e definir os indicadores;

- coletar e processar os dados;

- gerenciar a informação;

- avaliar e premiar; e

- revisar o sistema.

Foi realizado um pré-teste para aprimorar e validar o roteiro de entrevista, verificando a consistência da informação gerada - se os dados recolhidos eram necessários à pesquisa, bem como sua operatividade, vocabulário acessível e significado claro. A entrevista final ficou com 44 questionamentos, que foram aplicados a diferentes níveis da hierarquia das empresas.

\section{2a etapa: estudo de campo}

Para o estudo de campo as empresas foram escolhidas por conveniência segundo dois critérios:

(a) destaque de atuação no setor; e (b) maior grau de abertura com o pesquisador.

O primeiro critério foi estabelecido visando coletar uma amostra de empresas que possuíssem boas práticas de gestão, possibilidades de inovação gerencial e know-how acerca do tema em apreço. $\mathrm{O}$ segundo critério foi estabelecido exclusivamente para que a pesquisa fosse viável.

Todas as empresas possuem escopo de atuação semelhante, praça de atuação em Fortaleza e idades que variam de 7 a 40 anos, isto é, são empresas sólidas para as quais pressupõe-se a existência de processos gerenciais bem estabelecidos, seja em nível organizacional ou operacional (figurado pela metragem de área construída).

Foram realizadas dez entrevistas e seis tipos de documentação, conforme a Tabela 1.

\section{Análise de conteúdo}

A análise de conteúdo foi realizada, para os questionamentos abertos da entrevista, em quatro etapas, conforme Chizzoti (2011), Gibbs (2009) e Krippendorff (2004), e seguiu as etapas exemplificadas por Fossá (2003):

(a) pré-análise;

(b) exploração do material e o tratamento dos resultados;

(c) inferência e interpretação; e

(d) comparação entre os casos.

Na pré-análise realizaram-se a transcrição das entrevistas na íntegra e a leitura geral do material coletado (entrevistas e documentos), por caso. Este primeiro contato possibilitou a construção de um corpus de análise.

Em seguida, na exploração do material e tratamento dos resultados, realizou-se a formulação das categorias de análise, usando o referencial teórico e as indicações trazidas pela leitura geral. Para a elaboração das categorias de análise consideraram- 
se três critérios básicos: a exclusão mútua, a homogeneidade e a pertinência (FOSSÁ, 2003). Fez-se um recorte do material em unidades de registro (palavras, frases, parágrafos) comparáveis e com o mesmo conteúdo semântico e o agrupamento das unidades de registro nas categorias. O Quadro 2 apresenta o resultado desta etapa.

Na quarta etapa - inferência e interpretação -, obtiveram-se os indicadores da análise de conteúdo, bem como a triangulação dos documentos e entrevistas, compondo os resultados finais. Foram identificados 24 códigos, que juntos somam 39 menções e estão distribuídos em sete categorias, conforme a Tabela 2 .

Assim, na seção de resultados, apresenta-se apenas o resultado final desse processo. Já os questionamentos fechados foram realizados com a utilização de escala de Likert (RICHARDSON, 2011) com 5 pontos (de 1 a 5).

A tabulação dos dados foi dada como o total de pontos alcançados pela soma de cada nota dada por cada entrevistado dividido pela nota máxima atingível, caso todos indicassem como principal razão (ou seja, 5). A Tabela 3 apresenta um exemplo desse procedimento.

Como se pode observar, o somatório foi de 48 , dividido por 50, nota máxima caso todos os respondentes atribuíssem a nota 5 .

\section{Análise documental}

Os documentos foram utilizados para corroborar as informações da entrevista, garantido a validação da pesquisa por meio da triangulação de múltiplas fontes de evidência (YIN, 2010), e seguiu as recomendações de Cellard (2010) e Richardson (2011). Os documentos foram selecionados pelo critério de pertinência e fidedignidade, ou seja, consideraram-se como documentos apenas materiais formais da empresa, fornecidos pelos próprios entrevistados durante as entrevistas.

\section{3a etapa: oportunidades de melhorias}

Com as reflexões advindas dos estudos de caso foram identificadas lacunas de desempenho e oportunidades de melhoria tanto para as sistemáticas das empresas quanto para o campo do conhecimento.

Tabela 1 - Entrevistados/Documentos por empresa

\begin{tabular}{|c|c|c|c|c|c|}
\hline \multirow{2}{*}{ Empresa } & \multicolumn{2}{|c|}{ Entrevistados } & \multirow{2}{*}{ Total } & \multirow{2}{*}{$\begin{array}{c}\text { Documentação } \\
\text { Fornecida }\end{array}$} & \multirow{2}{*}{ Total } \\
\hline & Nível Estratégico & Nível Gerencial & & & \\
\hline Alfa & $\begin{array}{l}\text { Diretor Presidente } \\
\text { Diretor Financeiro }\end{array}$ & $\begin{array}{c}\text { Supervisor e } \\
\text { Representante da } \\
\text { Diretoria }\end{array}$ & 3 Entrevistas & Manual de Indicadores & 1 \\
\hline Tau & Diretor Técnico & $\begin{array}{l}\text { Representante da } \\
\text { Diretoria } \\
\text { Gerente Técnico }\end{array}$ & 3 Entrevistas & $\begin{array}{c}\text { Manual de procedimento } \\
\text { Ata de reunião de } \\
\text { indicadores } \\
\text { Relatório de } \\
\text { Benchmarking interno }\end{array}$ & 3 \\
\hline Beta & $\begin{array}{c}\text { Diretora de } \\
\text { Incorporação }\end{array}$ & $\begin{array}{l}\text { Gerente de } \\
\text { Planejamento e } \\
\text { Controller }\end{array}$ & 2 empresas & Relatórios de indicadores & 1 \\
\hline Gama & Diretor Técnico & Controller & 2 Entrevistas & Manual de Indicadores & 1 \\
\hline & & Total & 10 entrevistas & Total & 6 \\
\hline
\end{tabular}

\section{Quadro 2 - Exemplo da exploração do material e tratamento dos resultados da análise de conteúdo}

\footnotetext{
Diretor Presidente

1. O indicador de desempenho é fundamental para poder te avaliar, se você está melhorando

2. ou não. Se você não tiver um indicador de desempenho o que adianta sua empresa, por

3. exemplo ter desempenho financeiro, o que adianta você estar construindo bem,

4. construindo no prazo, atendendo as expectativas dos clientes se você não estiver ganhando

5. dinheiro? O retorno financeiro tem que vir. Também não adianta você construir,

6. ganhar dinheiro, construir no prazo se não atender a qualidade, pois assim, a longo

7. prazo você não se sustenta. Mais ou menos por aí que vejo o significado de

8. desempenho, para você poder se auto avaliar o tempo todo.
} 
Tabela 2 - Exemplo de categorias, conceitos norteadores e codificação utilizados na Análise de Conteúdo

\begin{tabular}{|c|c|c|c|c|c|c|c|c|c|c|c|c|}
\hline \multirow{2}{*}{ Categoria } & \multirow{2}{*}{$\begin{array}{l}\text { Conceito } \\
\text { Norteador }\end{array}$} & \multirow{2}{*}{$\begin{array}{c}\text { Código/ } \\
\text { Empresa/Entrevistado }\end{array}$} & \multicolumn{3}{|c|}{ Alfa } & \multicolumn{3}{|c|}{ Tau } & \multicolumn{2}{|c|}{ Beta } & \multicolumn{2}{|c|}{ Gama } \\
\hline & & & A & B & $\mathbf{C}$ & D & $\mathbf{E}$ & $\mathbf{F}$ & G & $\mathbf{H}$ & I & $\mathbf{J}$ \\
\hline \multirow{3}{*}{$\begin{array}{l}\text { Retorno } \\
\text { Financeiro }\end{array}$} & \multirow{3}{*}{$\begin{array}{l}\text { Resultado das } \\
\text { operações da } \\
\text { empresa em } \\
\text { dinheiro }\end{array}$} & Desempenho financeiro & 1 & & & & & & & & & \\
\hline & & Ganhar dinheiro & 2 & & & & & & & & & \\
\hline & & Retorno financeiro & 1 & & & & & & & & & \\
\hline \multirow{3}{*}{ Qualidade } & \multirow{3}{*}{$\begin{array}{l}\text { De acordo com as } \\
\text { especificações e } \\
\text { funcionalidades }\end{array}$} & Construir bem & 1 & & & & & & & & & \\
\hline & & Atender à qualidade & 1 & & & & & & & & & \\
\hline & & Inspeção na obra & & & & & & & & & & 1 \\
\hline \multirow[b]{2}{*}{ Prazo } & \multirow{2}{*}{$\begin{array}{c}\text { Tempo gasto para } \\
\text { realizar as } \\
\text { operações }\end{array}$} & Construir no prazo & 2 & 2 & & & & & & & & \\
\hline & & Obra no prazo & & & & & & & & & & 2 \\
\hline \multirow{6}{*}{$\begin{array}{l}\text { Satisfação dos } \\
\text { clientes }\end{array}$} & \multirow{6}{*}{$\begin{array}{c}\text { Como os clientes } \\
\text { nos veem }\end{array}$} & $\begin{array}{c}\text { Atender às expectativas } \\
\text { dos clientes }\end{array}$ & 1 & & & & & & & & & \\
\hline & & Agregar valor ao cliente & & & & 2 & & & & & & \\
\hline & & $\begin{array}{c}\text { Superar as expectativas } \\
\text { do cliente }\end{array}$ & & & & 1 & & & & & & \\
\hline & & Atender bem o cliente & & & & 1 & & & & & & \\
\hline & & Satisfação do cliente & & & & & & & & & & 4 \\
\hline & & Manutenção ser atendida & & & & & & & & & & 1 \\
\hline
\end{tabular}

Nota: Legenda:

A - Diretor 1;

B - Diretor 2;

C - Supervisor/ RD;

D - Diretor;

$\mathrm{E}-\mathrm{RD}$;

F - Gerente;

G - Diretora

H - Gerente;

I - Diretor; e

J - Controller.

Tabela 3 - Exemplo de tabulação por frequência das questões objetivas

\begin{tabular}{ccccccccccccc}
\hline Motivo/ Respondente & A & B & C & D & E & F & G & H & I & J & \multicolumn{2}{c}{ Consolidação } \\
\hline Gerir a estratégia & 5 & 5 & 4 & 5 & 5 & 4 & 5 & 5 & 5 & 5 & 48 & $96 \%$ \\
\hline
\end{tabular}

\section{Resultados e discussões}

A seguir realiza-se uma análise dos SMD das quatro empresas do estudo de caso. Inicialmente se apresentam as principais características das empresas, bem como sua visão sobre desempenho. Em seguida realiza-se uma análise das dimensões e dos indicadores de desempenho. Na sequência exploram-se os papéis e os processos dos SMD, e, por fim, são delineadas as oportunidades de melhoria.

\section{Características e visão das empresas sobre medição de desempenho e seu uso}

As principais características das empresas analisadas são apresentadas no Quadro 3.
Vê-se que as empresas possuem nicho de atuação semelhante e atuam em diferentes praças. A credibilidade foi a característica de maior valor para os clientes citada pelas empresas. Possivelmente, tal critério é fruto do nicho de mercado de alto padrão.

Percebe-se que a redução de custos e a entrega dos empreendimentos no prazo foram as melhorias de processos mais citadas pelas empresas para aumentar a competitividade. Ademais, como diferenciais competitivos foram citados principalmente a entrega no prazo e o relacionamento com o cliente (na comercialização e no pós-obra). E mais, o processo crítico mais mencionado foi justamente a entrega dos empreendimentos dentro do prazo. 
Quadro 3 - Principais características das empresas estudadas

\begin{tabular}{|c|c|c|c|c|}
\hline $\begin{array}{c}\text { Características/ } \\
\text { Empresa }\end{array}$ & Empresa Alfa & Empresa Tau & Empresa Beta & Empresa Gama \\
\hline $\begin{array}{l}\text { Atuação e nicho } \\
\text { de mercado }\end{array}$ & $\begin{array}{c}\text { Incorporação e } \\
\text { Construção de } \\
\text { Edifícios } \\
\text { Residenciais e } \\
\text { Comercial de } \\
\text { Classes A e B } \\
\end{array}$ & $\begin{array}{c}\text { Incorporação e } \\
\text { Construção de } \\
\text { Edifícios } \\
\text { Residenciais e } \\
\text { Comercial de } \\
\text { Classes A e B } \\
\end{array}$ & $\begin{array}{l}\text { Incorporação e } \\
\text { Construção de } \\
\text { Edifícios } \\
\text { Residenciais e } \\
\text { Comercial de } \\
\text { Classes A } \\
\end{array}$ & $\begin{array}{c}\text { Incorporação e } \\
\text { Construção de } \\
\text { Edifícios } \\
\text { Residenciais e } \\
\text { Comercial de } \\
\text { Classes A } \\
\end{array}$ \\
\hline Praça de atuação & $\begin{array}{c}\text { Fortaleza-CE, } \\
\text { Manaus-AM, Natal- } \\
\text { RN e em Campinas- } \\
\text { SP }\end{array}$ & Fortaleza-CE & $\begin{array}{l}\text { Fortaleza-CE e } \\
\text { Natal-RN }\end{array}$ & Fortaleza-CE \\
\hline $\begin{array}{c}\text { Características } \\
\text { valorizadas pelos } \\
\text { clientes } \\
\end{array}$ & $\begin{array}{c}\text { Credibilidade, } \\
\text { localização e } \\
\text { qualidade } \\
\end{array}$ & Credibilidade & Marca da empresa & $\begin{array}{l}\text { Qualidade e } \\
\text { inovação }\end{array}$ \\
\hline $\begin{array}{l}\text { Critérios de } \\
\text { competição }\end{array}$ & $\begin{array}{l}\text { Localização, custo } \\
\text { de construção, } \\
\text { marca da empresa, } \\
\text { credibilidade, } \\
\text { excelência técnica e } \\
\text { customização }\end{array}$ & $\begin{array}{l}\text { Credibilidade, } \\
\text { a qualidade e } \\
\text { os valores }\end{array}$ & $\begin{array}{c}\text { Solidez } \\
\text { financeira, } \\
\text { qualidade, prazo e } \\
\text { foco no cliente }\end{array}$ & $\begin{array}{l}\text { Qualidade e } \\
\text { inovação }\end{array}$ \\
\hline $\begin{array}{c}\text { Melhoria de } \\
\text { processos para } \\
\text { aumentar a } \\
\text { competitividade }\end{array}$ & $\begin{array}{c}\text { Gestão de custos de } \\
\text { obra, a aquisição de } \\
\text { novos terrenos, } \\
\text { cumprimento dos } \\
\text { prazos de entrega } \\
\text { dos } \\
\text { empreendimentos }\end{array}$ & $\begin{array}{l}\text { Racionalização } \\
\text { dos processos } \\
\text { construtivos }\end{array}$ & $\begin{array}{c}\text { Qualidade e } \\
\text { segurança das } \\
\text { entregas dentro do } \\
\text { prazo }\end{array}$ & $\begin{array}{l}\text { Reduzir seu custo } \\
\text { de construção }\end{array}$ \\
\hline $\begin{array}{c}\text { Diferenciais } \\
\text { competitivos }\end{array}$ & $\begin{array}{c}\text { Relacionamento } \\
\text { com o cliente, } \\
\text { proatividade da } \\
\text { empresa, } \\
\text { customização e } \\
\text { manutenção } \\
\text { programada pós- } \\
\text { obra } \\
\end{array}$ & $\begin{array}{c}\text { Melhor } \\
\text { atendimento ao } \\
\text { cliente, entrega } \\
\text { no prazo e } \\
\text { atendimento } \\
\text { pós-obra }\end{array}$ & Solidez financeira & $\begin{array}{c}\text { Qualidade, } \\
\text { inovação e prazo }\end{array}$ \\
\hline $\begin{array}{l}\text { Processos } \\
\text { críticos }\end{array}$ & $\begin{array}{l}\text { Regularização da } \\
\text { documentação do } \\
\text { registro do imóvel e } \\
\text { relacionamento com } \\
\text { imobiliárias e } \\
\text { corretores }\end{array}$ & $\begin{array}{l}\text { Padronização e } \\
\text { melhoria dos } \\
\text { processos } \\
\text { construtivos }\end{array}$ & $\begin{array}{l}\text { Entrega dos } \\
\text { empreendimentos } \\
\text { dentro do prazo }\end{array}$ & $\begin{array}{l}\text { Execução da } \\
\text { estrutura de } \\
\text { concreto }\end{array}$ \\
\hline $\begin{array}{l}\text { Envolvimento } \\
\text { com filosofias de } \\
\text { gestão }\end{array}$ & Construção enxuta & $\begin{array}{l}\text { Construção } \\
\text { enxuta e } \\
\text { construção } \\
\text { verde } \\
\end{array}$ & $\begin{array}{c}\text { Construção } \\
\text { enxuta e } \\
\text { construção verde }\end{array}$ & $\begin{array}{l}\text { Construção enxuta } \\
\text { (em implantação) }\end{array}$ \\
\hline Certificações & $\begin{array}{c}\text { PBQP-H A e ISO } \\
9000\end{array}$ & $\begin{array}{c}\text { ISO 9001, } \\
\text { PBQP-H, } \\
\text { Procel e Selo } \\
\text { de } \\
\text { Acessibilidade }\end{array}$ & $\begin{array}{l}\text { PBQP-H A, ISO } \\
9000 \text { e ISO } 14000\end{array}$ & $\begin{array}{c}\text { PBQP-H A e ISO } \\
9000\end{array}$ \\
\hline
\end{tabular}

Destaca-se que todas as empresas manifestaram possuir envolvimento com a construção enxuta (CE). A CE é uma filosofia de produção que aplica os princípios do Sistema Toyota de Produção na construção, foi proposta por Koskela (1992) e se constitui como um novo paradigma de produção. A 
indústria da construção civil fortalezense é reconhecida por ser um polo de aplicação de tal filosofia. A Empresa Tau, por exemplo, é um case internacional dessa filosofia. Tal característica é relevante, pois, segundo Cândido e Barros Neto (2017), a medição de desempenho no contexto da $\mathrm{CE}$ envolve diferentes indicadores e diferentes dimensões de desempenho para que consigam a transparência e a melhoria contínua.

Ademais, observa-se a difusão da construção verde que duas empresas mencionaram ter envolvimento. Por fim, em relação às características, destaca-se que todas as empresas possuem sistema de gestão da qualidade certificado (pelo menos pelo PBQP$\mathrm{H})$.

Em relação ao significado de desempenho, a Tabela 4 apresenta o resultado de sua análise. Nota-se que foi apresentada a porcentagem de cada significado em relação à empresa e de maneira consolidada. Por exemplo, a satisfação dos clientes para Empresa Alfa tem frequência 1 por ter sido identificada apenas uma vez. Sua porcentagem para a empresa é, portanto, 1 dividido por 20, que é o total de significados detectados para a Empresa Alfa. Analogamente se executou a porcentagem para o resultado consolidado.
Verifica-se que os respondentes não distinguiram claramente o significado do desempenho de seus benefícios. Não obstante, a satisfação do cliente foi diagnosticada como principal sinônimo de desempenho, o que corrobora a evolução tanto da indústria, que migrou de desempenho financeiro para aspectos qualitativos e relacionados aos clientes (KAPLAN; NORTON, 1992), quanto das empresas construtoras (JIN et al., 2013).

Essa evidência é complementada ao se observar a evolução da indústria da construção, na qual os clientes estão cada vez mais exigentes, levando a uma melhoria da cultura das empresas construtoras no que diz respeito à padronização e qualidade (surgimento do PBQP-H e ISO 9000, por exemplo), bem como a própria legislação do setor com o código de defesa do consumidor e mais recentemente com a norma de desempenho - NBR 15575 (ABNT, 2013).

\section{Papéis dos SMD das Empresas}

A Tabela 5 apresenta os motivos para o uso de indicadores de desempenho.

Tabela 4 - Resultado da análise de conteúdo para o significado de desempenho

\begin{tabular}{l|c|c|c|c|c|c|c|c|c|c}
\hline \multirow{2}{*}{ Significado/Empresa } & \multicolumn{2}{|c|}{ Alfa } & \multicolumn{2}{c|}{ Tau } & \multicolumn{2}{c|}{ Gama } & \multicolumn{2}{c|}{ Beta } & \multicolumn{2}{c}{ Consolidação } \\
\cline { 2 - 11 } & Freq. & \% & Freq. & \% & Freq. & \% & Freq. & \% & Freq. & \% \\
\hline Satisfação dos clientes & 1 & 5 & 4 & 40 & 5 & 63 & 0 & 0 & 10 & 26 \\
Competitividade & 3 & 15 & 4 & 40 & 0 & 0 & 1 & 100 & 8 & 21 \\
Prazo & 4 & 20 & 0 & 0 & 2 & 25 & 0 & 0 & 6 & 15 \\
Custo & 3 & 15 & 2 & 20 & 0 & 0 & 0 & 0 & 5 & 13 \\
Retorno financeiro & 4 & 20 & 0 & 0 & 0 & 0 & 0 & 0 & 4 & 10 \\
Marca da empresa & 3 & 15 & 0 & 0 & 0 & 0 & 0 & 0 & 3 & 8 \\
Qualidade & 2 & 10 & 0 & 0 & 1 & 13 & 0 & 0 & 3 & 8 \\
\hline \multicolumn{1}{c}{ Total } & $\mathbf{2 0}$ & $\mathbf{1 0 0}$ & $\mathbf{1 7}$ & $\mathbf{1 0 0}$ & $\mathbf{8}$ & $\mathbf{1 0 0}$ & $\mathbf{1}$ & $\mathbf{1 0 0}$ & $\mathbf{4 3}$ & $\mathbf{1 0 0}$ \\
\hline \multicolumn{2}{c}{} & & & & & & &
\end{tabular}

Tabela 5 - Motivos para o uso de indicadores de desempenho

\begin{tabular}{l|c|c}
\hline \multicolumn{1}{c|}{ Motivo } & $\boldsymbol{\Sigma}$ & \% Total \\
\hline 1. Gerir a estratégia & 48 & 96 \\
2. Dar apoio ao processo de gestão & 46 & 92 \\
3. Avaliar a evolução da empresa ao longo dos anos & 46 & 92 \\
4. Fornecer a situação real do desempenho e diagnóstico & 45 & 90 \\
5. Identificar áreas problemáticas e por que essas áreas são problemáticas & 45 & 90 \\
6. Proporcionar aprendizado e melhoria & 44 & 88 \\
7. Influenciar o comportamento & 43 & 86 \\
8. Comunicar resultados aos stakeholders & 41 & 82 \\
9. Identificar lacunas de desempenho e melhorias potenciais & 39 & 78 \\
10. Realizar benchmarking interno & 39 & 78 \\
11. Possibilitar uma análise de causa e efeito nas mudanças estruturais e ambientais & 38 & 76 \\
12. Realizar benchmarking externo & 38 & 76 \\
\hline
\end{tabular}


Verifica-se inicialmente que os motivos questionados nas entrevistas se mostraram aderentes. Nesse sentido, destaca-se o baixo vínculo dos indicadores com a prática de benchmarking. Isso é incongruente com o fato de as empresas terem manifestado vínculo com a filosofia da construção enxuta, cujo décimo primeiro princípio é realizar benchmarking (KOSKELA, 1992). Além disso, denota-se que as várias iniciativas de clube de benchmarking realizadas não foram bem-sucedidas, pelo menos no contexto da construção civil local. Isso representa uma oportunidade de melhoria ímpar para os SMD.

Ademais, todos os entrevistados compartilham do mesmo pensamento de que o uso exclusivo de indicadores financeiros não é suficiente para a tomada de decisão, corroborando Kaplan e Norton (1992), que afirmam que os gestores não devem ficar restritos em escolher as medidas financeiras e medidas operacionais; é importante que se consiga o equilíbrio entres elas. Todos os entrevistados também afirmaram que os indicadores são fundamentais para o alcance da melhoria contínua em suas empresas.

\section{Dimensões e indicadores de desempenho}

Dando continuidade à análise dos SMD das empresas, seus papéis devem ser suportados por indicadores de desempenho de diferentes dimensões de desempenho, conforme os motivos de seu uso.

A Empresa Alfa possui 13 indicadores, que estão organizados conforme as áreas funcionais da empresa e por sua abrangência (toda a empresa, matriz e obra) em contabilidade, DAC manutenção, qualidade, comercial, recursos humanos e obra.

Já a Empresa Tau organiza seus 18 indicadores conforme as perspectivas do BSC em aprendizagem e crescimento, processos internos, clientes e financeiro. Vale destacar ainda que esta empresa desenvolveu um indicador intitulado de auditoria Lean, que serve para avaliar o desempenho da aplicação da filosofia Lean Construcion, base da filosofia gerencial da empresa - esse indicador foi publicado por Valente et al. (2012), em que se pode melhor compreendê-lo.

A Empresa Beta possui 49 indicadores organizados nas áreas funcionais em clientes, pessoas, financeiro, marketing, comercial, projetos, qualidade, suprimentos, tecnologia da informação (TI) e obra. Por fim, a Empresa Gama possui 33 indicadores, divididos também pelas áreas funcionais e conforme a abrangência (obra, empresa e sala técnica) em compras, qualidade, recursos humanos, almoxarifado, sustentabilidade - obra, planejamento -, sala técnica, comercial, serviço de atendimento ao cliente, assistência técnica, segurança e financeiro.

Assim, vê-se que a organização dos indicadores quanto às dimensões ainda está fortemente atrelada à visão departamental e segmentada, o que dificulta sua integração. Na empresa Tau, no entanto, observa-se que diferentes indicadores vinculados a diferentes departamentos podem estar associados em uma mesma dimensão, ou seja, a visão integradora de que a perspectiva do cliente, por exemplo, possui uma contribuição não apenas do setor de relacionamento com o cliente em si.

Dos 113 indicadores identificados, apenas 14 encontram correspondência em mais de uma empresa analisada, os quais são apresentados na Tabela 6.

Observa-se que os principais indicadores (utilizados por pelo menos três empresas) estão relacionados às dimensões de qualidade, sustentabilidade, satisfação do cliente, custos e financeiro. Verificase que cinco deles estão vinculados a aspectos operacionais, e os demais, a aspectos estratégicos, o que corrobora o principal motivo para o uso dos indicadores apresentados anteriormente, que foi gerir a estratégia.

Ademais, todos os diretores afirmaram possuir o indicador de rentabilidade e lucratividade, porém os documentos fornecidos com os indicadores não comprovam sua existência formal no sistema de medição da empresa, o qual consta apenas na Empresa Alfa.

\section{Processos dos SMD das Empresas}

Por fim, analisam-se os processos dos SMD, conforme os cinco componentes mapeados por Franco-Santos et al. (2007), que são:

(a) seleção e definição dos indicadores;

(b) coleta e processamento;

(c) gerenciamento da informação;

(d) avaliação e premiação; e

(e) revisão sistemática.

\section{Seleção e definição dos indicadores}

O Quadro 4 apresenta as características da etapa de seleção e definição dos indicadores.

Observa-se que, em geral, as empresas possuem manual dos indicadores, à exceção da Empresa Tau. Os indicadores estão vinculados aos objetivos estratégicos, embora isso não tenha sido evidenciado pela Empresa Tau (não está explícito) 
e pela Empresa Beta (falta de documentação). Verifica-se ainda que a estratégia foi a principal fonte de seleção.

Quanto às dificuldades, observam-se falhas na seleção do indicador, que pode estar vinculada à falta de visão sistêmica dos gestores e até à forma como esses são selecionados (de cima para baixo, estratégico para operacional). Há dificuldade também na estrutura de definição, ou seja, no manual de indicadores, conforme observa o supervisor e representante da direção da Empresa Alfa, que informou que "a gente tem que estabelecer um indicador que realmente traduza a realidade. Às vezes você até busca muitos números, muitos indicadores, mas na realidade não são úteis de fato, não traduzem aquilo que você precisa”.

Além disso, o gerente técnico da Empresa Tau apontou como crítico o número de indicadores, quantidade que pode tergiversar a importância de cada um deles: "Eu acho que a gente precisa focar nos principais porque a gente fica tentado criar vários índices que no final não ajudam. Tomam mais tempo do que podem ajudar numa decisão”.

Tabela 6 - Consolidação de indicadores de desempenho das empresas

\begin{tabular}{|c|c|c|c|c|c|c|}
\hline \multirow{2}{*}{ Indicador/Empresa } & \multirow{2}{*}{ Alfa } & \multirow{2}{*}{ Tau } & \multirow{2}{*}{ Beta } & \multirow{2}{*}{ Gama } & \multicolumn{2}{|c|}{ Consolidação } \\
\hline & & & & & Freq. & $\%$ \\
\hline $\begin{array}{l}\text { Não Conformidade de execução de obra/cumprimento de } \\
\text { não-conformidades/ Índice de NC na obra }\end{array}$ & 1 & & 1 & 1 & 3 & 75 \\
\hline $\begin{array}{l}\text { Geração de resíduos ao longo da obra/Índice de resíduos da } \\
\text { construção (IRC) }\end{array}$ & 1 & 1 & & 1 & 3 & 75 \\
\hline $\begin{array}{l}\text { Nível de satisfação do cliente pós-ocupação/ Satisfação de } \\
\text { cliente obra entregue }\end{array}$ & 1 & & 1 & 1 & 3 & 75 \\
\hline $\begin{array}{l}\text { Inadimplência/Índice de inadimplência/Índice de } \\
\text { inadimplência x carteira }\end{array}$ & 1 & & 1 & 1 & 3 & 75 \\
\hline $\begin{array}{l}\text { Controle de custo por obra/índice de desvio de custo } \\
\text { (IDC)/IDC - Índice de desenvolvimento de custo }\end{array}$ & 1 & 1 & 1 & & 2 & 75 \\
\hline Vendas sobre ofertas/Velocidade sobre oferta (VSO líquido) & 1 & & 1 & & 2 & 50 \\
\hline Consumo de água ao longo da obra & 1 & & & 1 & 2 & 50 \\
\hline $\begin{array}{l}\text { Consumo de energia ao longo da obra/ Indicador de } \\
\text { consumo de energia ao longo da obra }\end{array}$ & 1 & & & 1 & 2 & 50 \\
\hline $\begin{array}{l}\text { Quantidade de reinspeção/Entrega do produto com qualidade } \\
\text { - recebimento }\end{array}$ & & & 1 & 1 & 2 & 50 \\
\hline Índice de velocidade de vendas (IVV) & & & 1 & 1 & 2 & 50 \\
\hline Índice de rotatividade & & & 1 & 1 & 2 & 50 \\
\hline $\begin{array}{l}\text { Índice de treinamento/ Índice de cumprimentos de } \\
\text { levantamento de necessidades de treinamento }\end{array}$ & 1 & & 1 & & 2 & 50 \\
\hline Retenção de pessoal/ Retenção (qualidade na seleção) & & & 1 & 1 & 2 & 50 \\
\hline Volume global de vendas/VGV regularizado & 1 & & & 1 & 2 & 50 \\
\hline
\end{tabular}

Fonte: adaptado dos documentos das empresas.

\section{Quadro 4 - Principais características da seleção e definição dos indicadores}

\begin{tabular}{|c|c|c|c|c}
\hline $\begin{array}{c}\text { Características/ } \\
\text { Empresa }\end{array}$ & Empresa Alfa & Empresa Tau & Empresa Beta & Empresa Gama \\
\hline $\begin{array}{c}\text { Possui manual } \\
\text { de indicadores }\end{array}$ & Sim & Não & $\begin{array}{c}\text { Sim, mas não } \\
\text { forneceu } \\
\text { documentação }\end{array}$ & Sim \\
\hline $\begin{array}{c}\text { Relação com os } \\
\text { objetivos } \\
\text { estratégicos }\end{array}$ & Sim & Não explicito & $\begin{array}{c}\text { Sim, mas não } \\
\text { forneceu } \\
\text { documentação }\end{array}$ & Sim \\
\hline $\begin{array}{c}\text { Forma de } \\
\text { seleção dos } \\
\text { indicadores }\end{array}$ & $\begin{array}{c}\text { A partir da estratégia } \\
\text { e do Sistema de } \\
\text { Gestão da Qualidade }\end{array}$ & $\begin{array}{c}\text { A partir da } \\
\text { benchmarking clube de } \\
\text { setorial e da } \\
\text { literatura }\end{array}$ & $\begin{array}{c}\text { A partir da estratégia } \\
\text { de gestão da } \\
\text { qualidade e de } \\
\text { consultorias } \\
\text { externas }\end{array}$
\end{tabular}

Fonte: elaborado com base nas entrevistas e documentos das empresas. 
Esse fenômeno, de dificuldade para a seleção e definição dos indicadores, encontra eco na literatura: na primeira fase histórica de aplicação da medição de desempenho o problema fundamental era a medição de coisas erradas. $\mathrm{Na}$ virada do século, porém, o problema estava relacionado à obsessão das empresas em medir tudo, ou seja, a medição como um fim em si mesmo (NEELY; BOURNE, 2000).

Assim, esforços devem ser envidados para a melhoria dessa etapa pela atuação na estrutura de definição e na quantidade de indicadores. Para a estrutura de definição recomenda-se o uso do modelo de manual de indicadores desenvolvido por Neely et al. (1997), que oferece uma estrutura consistente para a execução dessa etapa e que já encontra aplicação no âmbito da construção (KAGIOGLOU; COOPER; AQUAD, 2001).

Entre as melhorias sugeridas, o diretor da Empresa Gama afirma que é necessário delegar um responsável por todos os indicadores para que seja possível gerenciá-los e melhorá-los. Tal responsável pode também atuar nas outras melhorias propostas.

\section{Coleta e processamento dos indicadores}

O Quadro 4 apresenta as principais características para a etapa em análise.

Verifica-se que todas as empresas utilizam planilhas eletrônicas e possuem software específico, embora este não integre todos os setores, conforme a Empresa Alfa, que informa possuir um para a gestão da qualidade. Todos afirmaram que tal etapa é padronizada, porém não se pode constatar tal afirmativa para a Empresa Beta, uma vez que seus documentos não foram disponibilizados.

Todos acreditam que o uso de TI pode melhorar o processo de coleta e processamento. Porém, vale destacar a ressalva apontada pela gerente da Empresa Beta quanto ao custo associado à customização do software e a sua flexibilidade. Quanto à estratégia para motivar a coleta dos indicadores, observa-se a postura da Empresa Tau, cujo diretor técnico visita as obras da empresa com pauta específica: discussão dos indicadores de desempenho da obra.

Observou-se que todas as empresas manifestaram dificuldade na etapa. A dificuldade principal é a inserção dos indicadores na rotina dos gestores, como aponta o gerente técnico: “em alguns momentos é difícil entrar na rotina. E eu acho que talvez algumas pessoas precisariam participar mais das decisões para se motivar a alimentarem indicadores”. Já o supervisor e representante da direção da Empresa Alfa apontou que "existe uma rotina de atualização e às vezes a gente não tem esses indicadores no tempo que deveria ter, o pessoal atrasa. A dificuldade que eu relataria seria essa, de apuração e apropriação desses indicadores”.

\section{Quadro 5 - Principais características da coleta e processamento dos indicadores}

\begin{tabular}{|c|c|c|c|c|}
\hline $\begin{array}{c}\text { Características/ } \\
\text { Empresa }\end{array}$ & Empresa Alfa & Empresa Tau & Empresa Beta & Empresa Gama \\
\hline $\begin{array}{c}\text { Como são } \\
\text { coletados e } \\
\text { processados os } \\
\text { indicadores }\end{array}$ & $\begin{array}{c}\text { A empresa utiliza } \\
\text { planilhas eletrônicas } \\
\text { e um software } \\
\text { personalizado pela } \\
\text { empresa para a } \\
\text { Gestão da Qualidade }\end{array}$ & $\begin{array}{c}\text { A empresa utiliza } \\
\text { manuais em } \\
\text { planilhas eletrônicas } \\
\text { e software } \\
\text { especializado }\end{array}$ & $\begin{array}{c}\text { A empresa coleta } \\
\text { nanualmente e em } \\
\text { planilhas eletrônicas } \\
\text { no campo e software }\end{array}$ & $\begin{array}{c}\text { A empresa utiliza } \\
\text { lanilhas eletrônicas } \\
\text { e um software ERP } \\
\text { personalizado }\end{array}$ \\
\hline $\begin{array}{c}\text { A etapa é } \\
\text { padronizada }\end{array}$ & $\operatorname{Sim}$ & $\operatorname{Sim}$ & $\begin{array}{c}\text { Sim, sem } \\
\text { explicitação }\end{array}$ & $\operatorname{Sim}$ \\
\hline $\begin{array}{c}\text { O uso de TI } \\
\text { pode melhorar o } \\
\text { processo }\end{array}$ & $\begin{array}{l}\text { Sim: o uso de TI } \\
\text { melhora o processo } \\
\text { de coleta, tornando- } \\
\text { o mais ágil e } \\
\text { aumentando a } \\
\text { fidedignidade das } \\
\text { informações }\end{array}$ & $\begin{array}{l}\text { Sim: armazenar e } \\
\text { disponibilizar o } \\
\text { histórico dos } \\
\text { indicadores ao longo } \\
\text { da história da } \\
\text { empresa }\end{array}$ & $\begin{array}{l}\text { Sim, com ressalva } \\
\text { ao custo associado a } \\
\text { customização do } \\
\text { software e à sua } \\
\text { flexibilidade }\end{array}$ & $\operatorname{Sim}$ \\
\hline $\begin{array}{c}\text { Existe estratégia } \\
\text { para motivar a } \\
\text { coleta dos } \\
\text { indicadores }\end{array}$ & $\begin{array}{c}\text { A empresa já tentou } \\
\text { mecanismos } \\
\text { punitivos, mas a } \\
\text { questão ainda } \\
\text { suscita } \\
\text { aprimoramento }\end{array}$ & $\begin{array}{l}\text { Sim:o diretor } \\
\text { técnico vai à obra } \\
\text { discutir os } \\
\text { indicadores com o } \\
\text { respectivo gestor }\end{array}$ & $\begin{array}{l}\text { Sim: Existe um } \\
\text { cronograma de } \\
\text { atividades para } \\
\text { entrega da } \\
\text { informação }\end{array}$ & Não \\
\hline
\end{tabular}

Fonte: elaborado com base nas entrevistas e documentos das empresas. 
Por fim, para o controller da empresa Gama a dificuldade não está na coleta das informações em si, mas em seu processamento: "A estrutura é bem enxuta aqui e acaba que as pessoas ficam sobrecarregadas, não tendo o tempo hábil para poder entregar até o dia 10. O gargalo é na parte do processamento; colher as informações é fácil”.

Assim, verifica-se que ou os indicadores não refletem as necessidades de informações para o gerenciamento da empresa ou a forma como são coletados e processados é burocrática e demorada, tornando-se uma barreira a seu uso eficaz e eficiente. Deve-se, portanto, buscar estratégias para a inserção dos indicadores na rotina de gerenciamento da empresa, e o primeiro passo é avaliar se realmente os indicadores refletem o que a empresa precisa medir - o que conduz à etapa anterior de selecionar e definir os indicadores.

Por fim, destaca-se como oportunidade de melhoria a descentralização da coleta de dados, conforme o diretor técnico da Empresa Tau, que afirmou que antes a responsabilidade pela coleta dos indicadores era do escritório e que agora é atribuição de cada obra:

[...] a gente tentou rodar, há uns 3 ou 4 anos, de o escritório fazer esses indicadores, coletando da obra. E a gente viu que não era muito saudável, porque o gestor de obra [...] tem que entender que ele é o gestor. A obra é dele. Então ele tem o maior prazer do mundo de fazer o indicador e apresentá-lo. (Diretor Técnico da Empresa Tau).
Ademais, o representante da direção da Empresa Tau também apresentou duas sugestões para melhorar essa etapa de coleta e processamento dos indicadores:

(a) haver "sensibilização, treinamento e conscientização para que realmente cada colaborador compre [o indicador], isso é fundamental"; e

(b) facilitar a coleta, armazenamento e processamento de informações extraídas de forma artesanal, tais como a auditoria de qualidade de serviços (registro de prumo, esquadro e nível).

Esta segunda oportunidade de melhoria repete o uso integral ou a personalização dos softwares ERP, integrando-os ao sistema de medição, pois nem todos os indicadores são coletados ou fornecidos por este.

\section{Gerenciamento da informação}

O Quadro 6 apresenta as principais características da etapa de gerenciamento das informações.

O uso de reunião para debater os indicadores é unanimidade entre as empresas para a disseminação das informações que são disseminadas seletivamente. Na Empresa Tau, por exemplo, os resultados também são publicados para os stakeholders por meio do Relatório GRI (Global Reporting Initiative), que contém principalmente os indicadores referentes às ações de sustentabilidade desenvolvidas pela empresa.

\section{Quadro 6 - Principais características da etapa de gerenciamento da informação}

\begin{tabular}{|c|c|c|c|c|}
\hline $\begin{array}{l}\text { Características/ } \\
\text { Empresa }\end{array}$ & Empresa Alfa & Empresa Tau & Empresa Beta & Empresa Gama \\
\hline $\begin{array}{c}\text { Forma de } \\
\text { apresentação dos } \\
\text { indicadores }\end{array}$ & $\begin{array}{c}\text { Reuniões de } \\
\text { discussões entre } \\
\text { gerentes } \\
\text { mensalmente } \\
\text { etrimestralmente em } \\
\text { reuniões de análise } \\
\text { crítica }\end{array}$ & $\begin{array}{c}\text { Relatórios, reuniões } \\
\text { e painel na obra }\end{array}$ & $\begin{array}{l}\text { Reunião mensal de } \\
\text { consultores externos } \\
\text { com a diretoria; } \\
\text { reunião mensal de } \\
\text { diretoria com } \\
\text { gerência; reunião } \\
\text { bimestral com nivel } \\
\text { operacional; reunião } \\
\text { mensal na obra; } \\
\text { dashboard }\end{array}$ & $\begin{array}{c}\text { Reuniões de } \\
\text { discussões duas } \\
\text { vezes por mês, } \\
\text { tanto no escritório } \\
\text { como na obra }\end{array}$ \\
\hline $\begin{array}{l}\text { Disseminação } \\
\text { seletiva dos } \\
\text { resultados dos } \\
\text { indicadores }\end{array}$ & Sim & $\operatorname{Sim}$ & $\operatorname{Sim}$ & Sim \\
\hline $\begin{array}{l}\text { Uso externo das } \\
\text { informações dos } \\
\text { indicadores }\end{array}$ & $\begin{array}{l}\text { Sim: divulgação dos } \\
\text { resultados } \\
\text { financeiros e; } \\
\text { progresso fisico dos } \\
\text { empreendimentos }\end{array}$ & Sim: relatório GRI & $\begin{array}{l}\text { Sim: por ser uma } \\
\text { empresa de capital } \\
\text { aberto, há a } \\
\text { obrigatoriedade da } \\
\text { divulgação dos seus } \\
\text { resultados } \\
\text { financeiros. }\end{array}$ & $\begin{array}{c}\text { Sim: o } \\
\text { acompanhamento } \\
\text { de obras em seu } \\
\text { site }\end{array}$ \\
\hline
\end{tabular}

Fonte: elaborado com base nas entrevistas e documentos das empresas. 
As empresas Tau e Beta utilizam-se ainda de dispositivos visuais (dashboard) para a disseminação das informações, fato que pode estar relacionado à filosofia de gestão com que manifestaram ter envolvimento (construção enxuta), que prega o gerenciamento visual.

Todas as empresas possuem o andamento de seus empreendimentos divulgados em seus sites, mas nem todas reconhecem esse uso de informações como divulgação externa, como é o caso das Empresas Tau e Beta, o que se constitui uma oportunidade de melhoria.

Em relação às dificuldades na etapa na visão da gerente da Empresa Gama, o gerenciamento das informações consome muito tempo porque as informações não são gerenciadas via sistema ERP (Enterprise Resource Planning). Foi apontada também a quantidade de reuniões para disseminar as informações, o que consome muito tempo. E mais, conforme o supervisor e representante da direção da Empresa Alfa, as informações não chegam a todos os interessados, o que se constitui uma oportunidade de melhoria.

Como melhoria, destaca-se ainda a necessidade de aumentar a segurança com que a informação é repassada entre os diversos níveis hierárquicos, garantindo que a visão do gestor estratégico não seja distorcida quando chega ao nível tático, e do nível tático para o operacional, conforme o representante da direção da Empresa Tau.

\section{Avaliação e premiação}

O Quadro 7 apresenta as principais características da etapa de avaliação e premiação.

Todos os entrevistados afirmaram utilizar os indicadores para a tomada de decisão, e apenas a Empresa Beta não possui sistema de recompensa. Em geral, esses sistemas são voltados para a recompensa da administração da obra e são baseados nos indicadores de custo, prazo e qualidade.
Em relação às dificuldades, o diretor da Empresa Gama manifestou grande dificuldade para a premiação, pois não tem certeza de que seu sistema de recompensa é justo, e a forma para melhorar tal situação foi o benchmarking com parceiros:

Eu lhe confesso que não sei se o meu sistema que estou querendo fazer ou o sistema velho de premiação, qual é o mais justo. Eu não sei. E estamos conversando muito com os parceiros. Sinto que ninguém mostra muito como faz, ou porque não quer ensinar, ou tem medo de escancarar. (Diretor da Empresa Gama).

Verifica-se uma grande oportunidade de melhoria, pois a fala do diretor da Empresa Gama deixa claro como esse processo é frágil não apenas em sua empresa, mas para seus parceiros também. Esse fenômeno é observado explicitamente na literatura, conforme observam Cândido, Lima e Barros Neto (2016).

Alguns caminhos para a melhoria desse processo foram apontados pelo representante da direção que indica a "gestão por competências" como uma forma de melhorar a premiação. Assim, destacamse como melhorias apontadas: (a) atrelar a recompensa à gestão por
competência; e

(b) estabelecer metas e recompensas vinculadas a essas metas.

\section{Revisão sistemática}

O Quadro 8 apresenta as principais características para a etapa de revisão sistemática. Vale destacar que essa etapa diz respeito não apenas à revisão dos indicadores e de suas metas, mas ao próprio processo de medição de desempenho - se está sendo eficaz e eficiente, em vez de um processo burocrático que não agrega valor ao gerenciamento da empresa.

\section{Quadro 7 - Principais características da etapa de avaliação e premiação}

\begin{tabular}{|c|c|c|c|c|}
\hline $\begin{array}{c}\text { Características/ } \\
\text { Empresa }\end{array}$ & Empresa Alfa & Empresa Tau & Empresa Beta & Empresa Gama \\
\hline $\begin{array}{c}\text { Uso dos } \\
\text { indicadores na } \\
\text { tomada de } \\
\text { decisão }\end{array}$ & Sim & Sim & Sim & Sim \\
\hline $\begin{array}{l}\text { Existência de } \\
\text { sistema de } \\
\text { recompensa }\end{array}$ & $\begin{array}{l}\text { Sim, baseado nos } \\
\text { indicadores custo, } \\
\text { prazo, qualidade das } \\
\text { obras e gestão da } \\
\text { rotina de trabalho } \\
\text { para a administração } \\
\text { da obra }\end{array}$ & $\begin{array}{l}\text { Sim, para todos os } \\
\text { colaboradores da } \\
\text { empresa. Entretanto, } \\
\text { não foi observado } \\
\text { um processo } \\
\text { estruturado com } \\
\text { metas especificas } \\
\text { para as recompensas }\end{array}$ & Não & $\begin{array}{l}\text { Sim, baseado nos } \\
\text { indicadores custo, } \\
\text { prazo, qualidade e } \\
\text { segurança para a } \\
\text { equipe } \\
\text { administrativa da } \\
\text { obra }\end{array}$ \\
\hline
\end{tabular}

Fonte: elaborado com base nas entrevistas e documentos das empresas. 
Quadro 8 - Principais características da etapa de revisão sistemática

\begin{tabular}{|c|c|c|c|c|}
\hline $\begin{array}{c}\text { Características/ } \\
\text { Empresa }\end{array}$ & Empresa Alfa & Empresa Tau & Empresa Beta & Empresa Gama \\
\hline $\begin{array}{l}\text { Existência da } \\
\text { revisão } \\
\text { sistemática }\end{array}$ & Sim & $\mathrm{Sim}$ & Sim & Não há \\
\hline $\begin{array}{c}\text { Revisa os } \\
\text { indicadores e as } \\
\text { metas }\end{array}$ & $\begin{array}{c}\text { Anualmente apenas } \\
\text { para as metas. Os } \\
\text { indicadores são } \\
\text { revisados de forma } \\
\text { assistemática, por } \\
\text { meio de } \\
\text { necessidades } \\
\text { específicas }\end{array}$ & $\begin{array}{l}\text { Anualmente apenas } \\
\text { para as metas. Os } \\
\text { indicadores são } \\
\text { revisados de forma } \\
\text { assistemática, por } \\
\text { meio de } \\
\text { necessidades } \\
\text { específicas }\end{array}$ & $\begin{array}{l}\text { Anualmente apenas } \\
\text { para as metas. Os } \\
\text { indicadores são } \\
\text { revisados de forma } \\
\text { assistemática, por } \\
\text { meio de } \\
\text { necessidades } \\
\text { específicas }\end{array}$ & $\begin{array}{c}\text { Anualmente } \\
\text { apenas para as } \\
\text { metas. Os } \\
\text { indicadores são } \\
\text { revisados de forma } \\
\text { assistemática, por } \\
\text { meio de } \\
\text { necessidades } \\
\text { específicas }\end{array}$ \\
\hline $\begin{array}{c}\text { Revisa a } \\
\text { funcionalidade } \\
\text { do sistema de } \\
\text { medição }\end{array}$ & Não há & Não há & Não há & Não há \\
\hline
\end{tabular}

Fonte: elaborado com base nas entrevistas e documentos das empresas.

Verifica-se que a revisão que as empresas realizam não é sistemática. Quando ocorrem revisões, elas são direcionadas às metas, conforme observa o supervisor e representante da direção da Empresa Alfa: "Acho que não há uma rotina, talvez se estabelecesse uma periodicidade 'a cada ano você tem que fazer uma revisão’, ou pelo menos checar se aquele indicador está sendo útil”. O diretor 1 da mesma empresa complementa que, "quando um indicador começa a se tornar ineficiente, a própria pessoa que o manuseia não vai mais querer medilo”.

Na Empresa Tau o mesmo acontece. Por exemplo, o diretor técnico citou a criação de um indicador de soluções de projeto advindo da implantação e uso do BIM em sua empresa, mas não existe um mecanismo sistemático para inserção de novos indicadores na rotina da empresa.

Na Empresa Beta a revisão dos indicadores também não é sistematizada, como aponta a gerente: "Não. É assim, quando o diretor tem aquele sentimento de que aquilo não está funcionando [...] ele manda dar uma revisada, pensar de outra forma”. Tal fato também está presente na Empresa Gama, cujo diretor afirmou que "Não revisa[mos] sistematicamente. A partir das reuniões, [vamos] vendo as necessidades de revisão”.

Assim, não há uma revisão dos indicadores em si, muito menos da funcionalidade do sistema, confirmando o observado por Cândido, Lima e Barros Neto (2016). Em outras palavras, o estabelecimento de uma revisão sistemática pode equilibrar a importância do indicador e sua facilidade de utilização, pois não adianta ter um bom indicador, mas de difícil apuração (que demanda um esforço exagerado para sua operacionalização) e que não esteja disponível no momento adequado. Os entrevistados manifestaram o desejo de formalizar esse processo, e o primeiro passo em suas visões é o estabelecimento de uma frequência de revisão dos indicadores.

Essa análise comparativa subsidiou a identificação de oportunidades de melhorias, que foram identificadas ao longo da análise realizada e que são sumarizadas a seguir.

\section{Oportunidades de melhoria}

As oportunidades identificadas ao longo da análise dos SMD são sumarizadas a seguir, conforme a estrutura de Franco-Santos et al. (2007), que serviu para a análise dos processos de seleção e definição dos indicadores; coleta e processamento dos indicadores; gerenciamento da informação; avaliação e premiação; e revisão sistemática.

Para a seleção e definição dos indicadores:

(a) reconhecer o progresso físico do empreendimento divulgado no site de todas as empresas como um indicador para os clientes e inseri-lo no manual de indicadores;

(b) melhorar a estrutura de definição dos indicadores - para tal se recomenda a estrutura de Neely et al. (1997), que oferece uma estrutura consistente para a execução desta etapa e que já encontra aplicação no âmbito da construção (KAGIOGLOU; COOPER; AQUAD, 2001);

(c) incluir um indicador que avalie o grau de implantação da filosofia de gestão utilizada pelas empresas - como a Empresa Tau, em Valente et al. (2012); 
(d) envolver todos os stakeholders internos na seleção dos indicadores da empresa, condicionando um processo em duas direções (da diretoria para a operação e da operação para diretoria) - verificou-se distorção entre a importância dada aos indicadores nos diferentes níveis hierárquicos, chegando ao ponto de gestores operacionais dizerem que existiam indicadores em que eles não confiavam; e

(e) formalizar todos os indicadores em um manual de utilização - verificou-se que as empresas manifestaram o uso de indicadores que não foram identificados nos documentos delas.

Para a coleta e processamento dos indicadores:

(a) estimular uma cultura de medição entre os gestores, reforçando o papel dos indicadores para auxiliar o gerenciamento da rotina e do cumprimento dos objetivos das empresas; e

(b) investir em automatização da coleta e processamento dos indicadores por meio de TI, salvaguardando a flexibilidade que o sistema precisa possuir para adaptar-se rapidamente às mudanças impostas pelo mercado.

Para o gerenciamento da informação:

(a) usar ferramenta de gerenciamento visual para disseminação das informações - uso de dashboard e painel em obra, por exemplo; e

(b) aumentar a segurança com que as informações são repassadas entre os níveis hierárquicos.

Para a avaliação e premiação: elaborar um sistema de recompensas baseado na gestão por competências com metas bem estabelecidas e repassadas aos responsáveis pelo processo para evitar injustiças quanto as bonificações.

Para a revisão sistemática: elaborar um processo de revisão sistemática com frequência predefinida e com foco não apenas nas metas dos indicadores, mas na importância do indicador em si e sua facilidade de operacionalização em termos de tempo e custo para sua manutenção no sistema.

Essas onze oportunidades de melhoria podem ajudar as empresas a serem mais competitivas, além de serem sugestivas para o âmbito do campo do conhecimento. Elas constituem a principal contribuição deste trabalho.

\section{Conclusão}

Este trabalho teve por objetivo analisar por meio de um estudo de caso múltiplo e exploratório as características, os papéis e os processos dos sistemas de medição de desempenho de quatro empresas de construção civil da cidade de Fortaleza, CE.
Por meio dos estudos de caso foi possível mapear o processo das empresas em questão. Em relação ao uso dos indicadores observou-se excesso de indicadores, que, na opinião de alguns gestores, não representavam necessariamente as demandas de apoio à gestão, gerando sobrecarga de trabalho por gerar indicadores não úteis, em detrimento dos indicadores de fato relevantes, o que dispersa o foco da análise e os desdobramentos efetivos acerca das ações a partir deles. O maior número de oportunidades de melhoria identificadas nessa etapa evidencia que ela é a principal lacuna de desempenho.

Destaca-se ainda que não foi identificada nenhuma prática de revisão sistemática dos indicadores, mas sim de suas metas, o que corrobora Cândido, Lima e Barros Neto (2016). E mais, todas as empresas devem envolver os níveis táticos/operacionais para que essa revisão seja efetivamente realizada, evitando-se distorções entre os níveis hierárquicos delas.

Ficou evidente, ainda, que os benefícios dos clubes de benchmarking amplamente difundidos na literatura não alcançaram sua plenitude, sendo um caminho importante para a melhoria do desempenho das empresas e do próprio setor de construção.

Conclui-se que os sistemas de medição podem ser refinados para proporcionar um estilo de gestão proativo para as mudanças do mercado e aumentar sua capacidade competitiva. O que se observou foi um exercício de gestão centrado em controles que não necessariamente dão oportunidades de melhoria para a empresa, mas apenas de reação às falhas ocorridas.

Apesar do esforço envidado e das contribuições desta pesquisa, merecem relevo as suas limitações, que se relacionam principalmente à natureza do trabalho qualitativo. Estudos de caso são oportunos para se aprofundarem fenômenos particulares, objetivando induzir proposições teóricas que possam ser verdade em outros contextos.

Por fim, para trabalhos futuros sugere-se:

(a) realizar uma survey para detectar quais as principais dificuldades e barreiras que as empresas construtoras encontram para a prática da medição de desempenho; e

(b) propor um sistema de gestão de indicadores capaz de captar as relações de causa e efeito entre medidas operacionais e estratégicas. 


\section{Referências}

ASMAR, M.; HANNA, A. S.; LOH, W. Evaluating Integrated Project Delivery Using the Project Quarterback Rating. Journal of Construction Engineering, v. 142, n. 1, p. 1-13, 2016.

\section{ASSOCIAÇÃO BRASILEIRA DE NORMAS \\ TÉCNICAS. NBR 15575: edificações}

habitacionais: desempenho. Rio de Janeiro, 2013.

BACCARINI, D. The Logical Framework Method for Defining Project Success. Project

Management Journal, v. 30, n. 4, p. 25-32, 1999.

BARBOSA, A. S. Uso de indicadores de Desempenho nas Empresas Construtoras Brasileiras: diagnóstico e orientações para utilização. São Carlos, 2010. 273 f. Tese (Doutorado em Engenharia de Produção) - Escola de Engenharia, Universidade de São Paulo, São Carlos, 2010.

BARRETO, A. M. Gestão da Informação: ferramenta da produção ou da significação? Informação \& Sociedade: Estudos, v. 16, n. 2, p. 51-61, 2006.

BASSIONI, H. A.; PRICE, A. D. F.; HASSAN, T. M. Building a Conceptual Framework for Measuring Business Performance in Construction: an Empirical Evaluation. Construction

Management and Economics, v. 23, n. 5, p. 495507, 2005.

BELTRÃO, R. E. V.; NOGUEIRA, F. DO, A. A Pesquisa Documental nos Estudos Recentes em Administração Pública e Gestão Social no Brasil. In: ENCONTRO NACIONAL DOS PROGRAMAS DE PÓS-GRADUAÇÃO E PESQUISA EM ADMINISTRAÇÃO, 35., Rio de Janeiro, 2011. Anais... Rio de Janeiro: Anpad, 2011.

BITITCI, U. S.; CARRIE, A. S.; MCDEVITT, L. Integrated Performance Measurement Systems: a development guide. International Jounal of Operations \& Production Management, v. 17, n. 5, p. 522-534, 1997.

CÂNDIDO, L. F.; BARROS NETO, J. de P. Features, Roles and Processes of Performance Measurement in Lean Construction. In: LEAN \& COMPUTING IN CONSTRUCTION CONGRESS, Helsinki, 2017. Proceedings... Heraklion: IGLC, 2017.

CÂNDIDO, L. F.; LIMA, S. H. de O.; BARROS NETO, J. de P. Análise de Sistemas de Medição de Desempenho na Indústria da Construção.

Ambiente Construído, Porto Alegre, v. 16, n. 2, p. 189-208, abr./jun. 2016.
CELLARD, A. A análise Documental. In: POUPART, J. et al. (Orgs.). A Pesquisa Qualitativa: enfoques epistemológicos e metodológicos. Petrópolis: Vozes, 2010.

CHIESA, V.; FRATTINI, F. Exploring the Differences in Performance Measurement Between Research and Development: evidence from a multiple case study. R\&D Management, v. 37, n. 4, p. 283-301, 2007.

CHIZZOTI, A. Pesquisa Qualitativa em Ciências Humanas e Sociais. 6. ed. Petrópolis: Vozes, 2011.

CHOONG, K. K. Has this Large Number of Performance Measurement Publications Contributed to Its Better Understanding? A systematic review for research and applications. International Journal of Production Research, v. 52, n. 14, p. 4174-4197, 2013a.

CHOONG, K. K. Understanding the Features of Performance Measurement system: a literature review. Measuring Business Excellence, v. 17, n. 4, p. 102-121, 11 nov. 2013b.

COLLIS, J.; HUSSEY, R. Pesquisa em

Administração: um guia prático para alunos de graduação e pós-graduação. 2. ed. Porto Alegre: Bookman, 2005.

COOPER, D. R.; SCHINDLER, P. S. Métodos de Pesquisa em Administração. 12. ed. Porto Alegre: AMGH, 2016.

COSTA, D. B. Diretrizes Para Concepção, Implementação e Uso de Sistemas de Indicadores de Desempenho Para Empresas da Construção Civil. Porto Alegre, 2003. 176 f. Dissertação (Mestrado em Engenharia Civil) Programa de Pós-Graduação em Engenharia Civil, Universidade Federal do Rio Grande do Sul, Porto Alegre, 2003.

COSTA, D. B. et al. Performance Measurement Systems for Benchmarking in the Construction Industry. In: ANNUAL CONFERENCE OF THE INTERNATIONAL GROUP FOR LEAN CONSTRUCTION, 12., Copenhaguen, 2004. Proceedings... Copenhaguen: IGLC, 2004.

COSTA, D. B. et al. Benchmarking Initiatives in the Construction Industry: lessons learned and improvement opportunities. Journal of Management in Engineering, v. 22, n. 4, p. 158167, 2006.

DENG, F.; SMYTH, H.; ANVUUR, A. A Critical Review of PMS in Construction: towards a research agenda. In: ANNUAL ARCOM CONFERENCE, 28., Edinburgh,2012. Proceedings... Edinburgh: ARCOM, 2012. 
EL-MASHALEH, M. S.; MINCHIN JUNIOR, R. E.; O’BRIEN, W. J. Management of Construction Firm Performance Using Benchmarking. Journal of Management in Engineering, v. 23, n. 1, p. 10-17, 2007.

EVANS, J. R. An Exploratory Study of Performance Measurement Systems and Relationships With Performance Results. Journal of Operations Management, v. 22, n. 3, p. 219232, 2004.

\section{EUROPEAN FOUNDATION FOR QUALITY MANAGEMENT. The EFQM Excellence} Model. Disponível em: <http://www.efqm.org/theefqm-excellence-model>. Acesso em: 24 jun. 2017.

FOSSÁ, M. I. T. A Cultura de Devoção nas Empresas Familiares e Visionárias: uma definição teórica e operacional. Porto Alegre, 2003. 312 f. Tese (Doutorado em Engenharia de Administração) - Programa de Pós-Graduação em Administração, Universidade Federal do Rio Grande do Sul, Porto Alegre, 2003.

FRANCO-SANTOS, M. et al. Towards a Definition of a Business Performance Measurement System. International Journal of Operations \& Production Management, v. 27, n. 8, p. 784-801, 2007.

FRANCO-SANTOS, M.; LUCIANETTI, L.; BOURNE, M. Contemporary Performance Measurement Systems: a review of their consequences and a framework for research.

Management Accounting Research, v. 23, n. 2, p. 79-119, 2012.

GEORGY, M. E.; CHANG, L.-M.; ZHANG, L. Utility-Function Model for Engineering Performance Assessment. Journal of Construction Engineering and Management, v. 131, n. 5, p. 558-568, 2005.

GHALAYINI, A. M.; NOBLE, J. S. The Changing Basis of Performance Measurement. International Journal of Operations \& Production Management, v. 16, n. 8, p. 63-80, 1996.

GIBBS, G. Análise de Dados Qualitativos. Porto Alegre: Artmed, 2009.

GIL, A. C. Métodos e Técnicas de Pesquisa

Social. 6. ed. São Paulo: Atlas, 2008.

GRAY, D. E. Pesquisa no mundo real. 2. ed. Porto Alegre: Penso, 2012.

HORSTMAN, A.; WITTEVEEN, W. Performance Indicators in the Best Value Approach. Advanced of Performance Information \& Value, v. 5, n. 2, p. 59-78, 2013.
HORTA, I. M.; CAMANHO, A. S.; COSTA, J. M. Performance Assessment of Construction Companies Integrating Key Performance Indicators and Data Envelopment Analysis. Journal of Construction Engineering and Management, v. 136, n. 5, p. 581-594, 2010.

HU, X.; LIU, C. Profitability Performance Assessment in the Australian Construction Industry: a global relational two-stage DEA method. Construction Management and Economics, v. 34, n. 3, p. 147-159, 2016.

JIN, Z. et al. Practical Framework for Measuring Performance of International Construction Firms. Journal of Construction Engineering and Management, v. 139, n. 9, p. 1154-1167, 2013.

KAGIOGLOU, M.; COOPER, R.; AQUAD, G. Performance Management in Construction: a conceptual framework. Construction

Management and Economics, v. 19, n. 1, p. 8595, 2001.

KAPLAN, R. S.; NORTON, D. P. The Balanced Scorecard: measures that drive performance. Havard Business Review, v. 70, n. 1, p. 70-79, 1992.

KAPLAN, R. S.; NORTON, D. P. Using the Balanced Scorecard as a Strategic Management System. Harvard Business Review, v. 74, n. 1, p. 75-85, 1996.

KORDE, T.; LI, M.; RUSSELL, A. D. State-ofthe-Art Review of Construction Performance Models and Factors. In: CONSTRUCTION RESEARCH CONGRESS, San Diego, 2005. Proceedings... San Diego: ASCE, 2005.

KOSKELA, L. Application of the New Production Philosophy to Construction. Stanford: Techniccal Repport 72. Center for Integrated Facility Engineering. Department of Civil Engineering. Stanford Univeristy, 1992.

KRIPPENDORFF, K. Content Analysis: an introduction to its methodology. 2. ed. London: Sage, 2004.

KUENG, P.; ANDREAS, M.; WTTSTEIN, T. Performance Measurement Systems Must be Engineered. Communications of the Association for Information Systems, v. 7, n. 3, p. 1-27, 2001.

KUHL, M. R.; KUHL, C. A.; GUSMÃO, I. B. Perfil do Desempenho das Maiores Empresas do Brasil. Revista Capital Científico - Eletrônica (RCCe), v. 12, n. 2, 2014.

LEBAS, M. J. Performance Measurement and Performance Management. International Journal of Production Economics, v. 41, n. 1, p. 23-35, 1995. 
LOHMAN, C.; FORTUIN, L.; WOUTERS, M. Designing a Performance Measurement System: a case study. European Journal of Operational Research, v. 156, n. 2, p. 267-286, Jul. 2004.

MAYA, R. A. Performance Management for Syrian Construction Projects Performance Management For Syrian Construction Projects. International Journal of Construction Engineering and Managament, v. 5, n. 3, p. 6578, 2016.

MELNYK, S. A.; STEWART, D. M.; SWINK, M. Metrics and Performance Measurement in Operations Management: dealing with the metrics maze. Journal of Operations Management, v. 22, n. 3, p. 209-217, 2004.

NEELY, A. et al. Performance Measurement System Design: developing and testing a processbased approach. International Journal of Operations \& Production Management, v. 20, n. 10, p. 1119-1145, 2000.

NEELY, A.; BOURNE, M. Why Measurement Initiatives Fail. Measuring Business Excellence, v. 4, n. 4, p. 3-7, 2000.

NEELY, A. et al. Designing Performance Measures: a structured approach. International Journal of Operations \& Production Management, v. 17, n. 11, p. 1131-1152, 1997.

NEELY, A.; GREGORY, M.; PLATTS, K. Performance Measuremente System Design: a literature review and research agenda.

International Journal of Operations \& Production Management, v. 15, n. 4, p. 80-116, 1995.

NUDURUPATI, S.; ARSHAD, T.; TURNER, T. Performance Measurement in the Construction Industry: an action case investigating manufacturing methodologies. Computers in Industry, v. 58, n. 7, p. 667-676, Sep. 2007.

RICHARDSON, R. J. Pesquisa Social: métodos e técnicas. 3. ed. São Paulo: Atlas, 2011.

ROBINSON, H. S. et al. Business Performance Measurement Practices in Construction Engineering Organisations. Measuring Business Excellence, v. 9, n. 1, p. 13-22, 2005.
ROESCH, S. A. Projetos de Estágio e de Pesquisa em Administração: guia para estágios, trabalhos de conclusão, dissertações e estudos de caso. 3. ed. São Paulo: Atlas, 2006.

SAIDI, K. S.; LYTLE, A. M.; STONE, W. C. Report of the NIST Workshop on Data Exchange Standards at the Construction Job Site. In: INTERNATIONAL SYMPOSIUM ON AUTOMATION AND ROBOTICS IN CONSTRUCTION, 20., Eindhoven, 2003. Proceedings... Eindhove: Technische Universiteit Eindhoven, 2003.

SCANLIN, J. The Internet as an Enabler of the Bell Atlantic Project office. Project Management Journal, v. 29, n. 2, p. 6-7, 1998.

SINK, D. S.; TUTTLE, T. C. Planejamento e Medição Para Performance. Rio de Janeiro: Qualitymark, 1993.

TATICCHI, P.; TONELLI, F.; CAGNAZZO, L. Performance Measurement and Management: a literature review and a research agenda.

Measuring Business Excellence, v. 14, n. 1, p. 418, 2010.

TONI, A.; TONCHIA, S. Performance Measurement Systems: models, characteristics and measures. International Jounal of Operations \& Production Management, v. 21, n. 1-2, p. 46-70, 2001.

VALENTE, C. P. et al. Lean Monitoring and Evaluation in a Construction Site: a proposal of lean audits. In: ANNUAL CONFERENCE OF THE INTERNATIONAL GROUP FOR LEAN CONSTRUCTION, 20., San Diego, 2012. Proceedings... San Diego: IGLC, 2012.

WEGELIUS-LEHTONEN, T. Performance Measurement in Construction Logistics. International Journal of Production Economics, v. 69, n. 1, p. 107-116, 2001.

YIN, R. K. Estudo de Caso: planejamento e métodos. 4. ed. Porto Alegre: Bookman, 2010.

YU, I. et al. Comparable Performance Measurement Sytem for Construction Companies. Journal of Management in Engineering, v. 23, n. 3, p. 131-139, 2007. 


\section{Domingos Sávio Viana de Sousa}

Programa de Pós-Graduação em Engenharia Civil: Estruturas e Construção Civil, Departamento de Engenharia Estrutural e Construção Civil | Universidade Federal do Ceará | Campus do Pici, s/n, Bloco 710 | Fortaleza - CE - Brasil | CEP 60455-760 | Tel.: (85) 3366-9600 |

E-mail: saviovshalom@gmail.com

\section{Luis Felipe Cândido}

Núcleo de Tecnologia | Centro Universitário Christus | Av. Dom Luis, 911, Aldeota, Campus Dom Luís | Fortaleza - CE - Brasil | CEP 60160196| Tel.: (85) 3457-5300 | E-mail: luisfcandido2015@gmail.com

\section{J osé de Paula Barros Neto}

Departamento de Engenharia Estrutural e Construção Civil, Centro de Tecnologia | Universidade Federal do Ceará |

E-mail: barrosneto@gercon.ufc.br

\section{Revista Ambiente Construído}

Associação Nacional de Tecnologia do Ambiente Construído

Av. Osvaldo Aranha, 99 - 30 andar, Centro

Porto Alegre - RS - Brasil

CEP 90035-190

Telefone: +55 (51) 3308-4084

Fax: +55 (51) 3308-4054

www. seer. ufrgs. br/ ambienteconstruido

E-mail: ambienteconstruido@ufrgs.br 